\title{
Thermal Characteristics of Oxazolidone Modified Epoxy Anhydride Blends
}

\author{
Anuradha Varshney ${ }^{1}$, Rashmi Mohan Mathur ${ }^{1} \&$ Kiran Prajapati ${ }^{2}$ \\ ${ }^{1}$ Department of Chemistry, Dayanand Girl's P. G. College, Kanpur (UP), India \\ ${ }^{2}$ Department of Chemistry, Government Girls Inter College, Singhpur, Kanpur, India \\ Correspondence: Anuradha Varshney, Department of Chemistry, Dayanand Girl's P. G. College, Kanpur (UP), \\ India. E-mail: varshney_anuradha@rediffmail.com
}

Received: November 25, $2011 \quad$ Accepted: December 19, $2011 \quad$ Online Published: May 27, 2012

doi:10.5539/ijc.v4n3p113 URL: http://dx.doi.org/10.5539/ijc.v4n3p113

\begin{abstract}
Oxazolidone modified epoxy resin blends can be prepared with dianhydrides to form thermosets with higher thermal stability. Curing the oxazolidone modified resin is an addition reaction, which offers better thermal properties and improved chemical resistance. Chemical reactions that take place during cure, determine resin morphology and properties of cured thermosets. Such epoxy resin systems are used for various reinforcements because they offer significant advantage over metals in area of weight saving and corrosion resistance and for use in glass fabric reinforced flame retardants.
\end{abstract}

Keywords: modified epoxy resin, oxazolidone, diianhydrides, epoxy anhydride blends, thermogravimetric analysis, thermal stability

\section{Introduction}

Oxazolidones are synthesized by polyaddition reaction between di isocyanates and di epoxies, forming linear thermoplastic polymers (Hong \& Wu, 2000). In this work, Diglycidal Ether of Bisphenol A (DGEBA) was modified using Tolylene 2,6 Diisocyanate (TDI) to give oxazolidone modified epoxy. Oxazolidone incorporated linear epoxy resins were cured with Benzophenone Tetracarboxylic Dianhydride (BTDA) to obtain high temperature resistant thermosets (Santoshi \& Shinichi, 2001). The crosslinking of these linear thermoplastic oxazolidones with dianhydrides results in the formation of insoluble and infusible cross linked thermosets which possess better thermal stability (Jamshldi \& Talemi, 2006; Javni, Guo, \& Petrovic, 2003; Chan \& Yi, 2001).

Anhydrides today are a major class of curing agents for epoxies because epoxy-anhydride systems exhibit low viscosity and long pot life, low exothermic heats of reaction and little shrinkage when cured at elevated temperatures, hence anhydride curing systems are used for curing epoxies to obtain higher thermal stability.

The properties of oxazolidone modified epoxies can be tailored by the choice of suitable amount of curing agents, as a result, the ratio of the epoxy to the anhydride becomes an important factor in deciding the final material performance. Temperature is a major influence on cure conditions.

\section{Materials \& Methods}

Cycloaddition of diisocyanate to diepoxies results in the formation of linear oxazolidone modified epoxy resin (Petrovic \& Javni, 2002; Callie, Pascault, \& Tighzert, 1990; Merline, Reghunadhan Nair, Gouri, Sadhana, \& Ninan, 2007; Frisch, Sendijarevic, \& Sendijarevic, 1987; Dušek, 1986). 


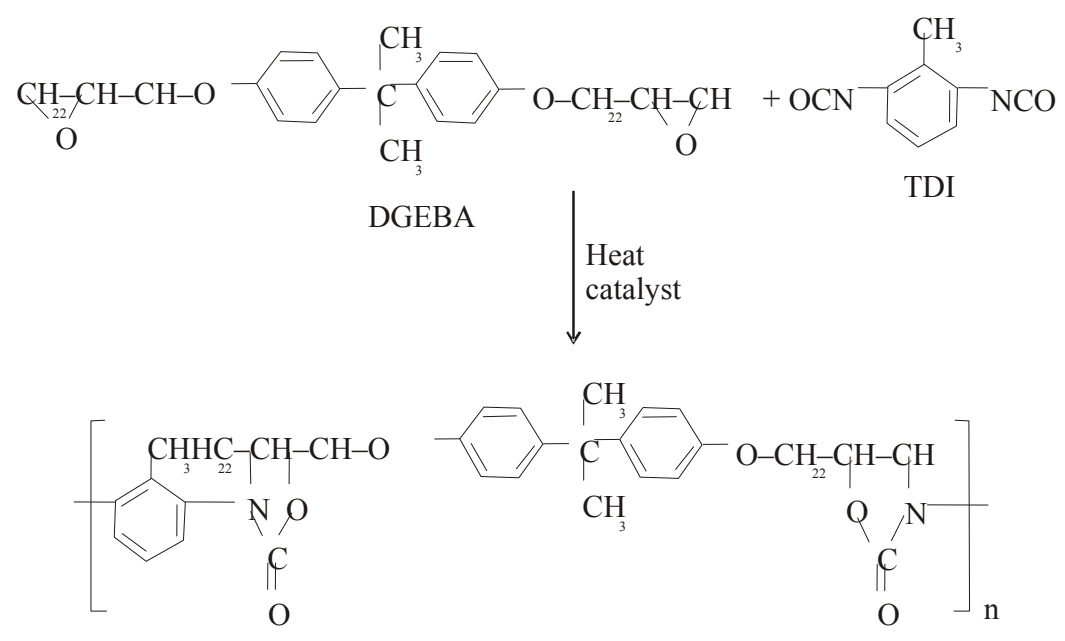

TDI modified oxazolidone

This reaction was conducted in solution, using N,N Dimethyl Formamide (DMF) as solvent and the product was characterized by Fourier Transform Infra Red Spectroscopy (FTIR) Figure 1. FTIR of the synthesized polymer shows characteristic peak for oxazolidone at $1754 \mathrm{cms}^{-1}$ whereas the peak for DGEBA at $915 \mathrm{cms}^{-1}$ is almost nonexistent, indicating that all the epoxy groups have been consumed. Peak for isocyanate at $2270 \mathrm{cms}^{-1}$ is also absent, indicating that all the isocyanate has reacted with epoxy to produce oxazolidones.

1) Benzophenone Tetracarboxylic Di anhydride (BTDA)

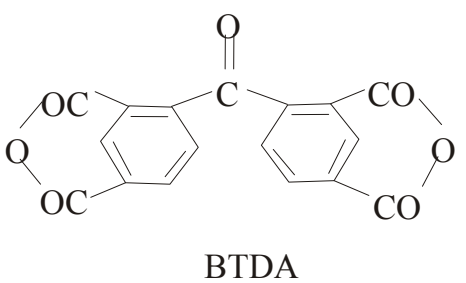

\subsection{Preparation of Anhydride Blends Using Benzophenonetetracarboxylic Dianhydride (BTDA)}

Benzophenone tetracarboxylic dianhydride (BTDA) is a multifunctional anhydride for use in high temperature applications (Hong \& Wu, 2000). Diglycidal ether of Bisphenol A (DGEBA) was heated to $80{ }^{\circ} \mathrm{C}$ and a weighed quantity of oxazolidone was added with continuous stirring and temperature was increased to $100{ }^{\circ} \mathrm{C}$ till the oxazolidone dispersed completely in the epoxy. The anhydride was added gradually, along with $1 \mathrm{phr}$ of the amine - Benzyl dimethyl amine (BDMA) as a catalyst. After stirring to get an evenly dispersed solution, the blends were poured into preheated and pretreated moulds. Curing was carried out at $130{ }^{\circ} \mathrm{C}$ for 4 hours. Post curing was carried out at $200{ }^{\circ} \mathrm{C}$ for 6 hours (Cole, 1991; Jan-Eric et al., 2007; Steven, Guy Van, Vuchelen, \& Bruno, 2005; Wei \& Delmar, 2004; Woo, \& Seferis, 2003; Min, Stachurski, Hodgkin, \& Heath, 1993; Min, Stachurski, Hodgkin, \& Heath, 1993; Min, Stachurski, Hodgkin, \& Heath, 1993).

Theoretically, a cross-linked thermoset polymer structure is obtained when equimolar quantities of resin and hardener are combined (Poisson, Lachenal, \& Sautereau, 1996). However, in practical applications, epoxy formulations are optimized for desired performance rather than to complete stoichiometric cures. In this work, blends were prepared using $1 \%, 5 \%, 10 \%, 15 \%, 25 \%$, and $50 \%$ of oxazolidone and the cured sample was then evaluated for thermal stability using Thermogravimetric Analysis (TGA) (Miren Blanco, Angeles, Carmen, Riccardi, \& Iñaki Mondragon, 2005; Min, Stachurski, \& Hodgkin, 1993; Poisson et al., 1996).

\section{Results and Discussions}

In epoxy-anhydride curing reaction, less than stoichiometric ratios of curing agents are used because of significant homopolymerization. The epoxy terminated oxazolidone is converted by means of a crosslinking reaction into a three dimensional hard thermoset (Younes, Wartewig, Lellinger, Strehmel, \& Strehmel, 1994). 


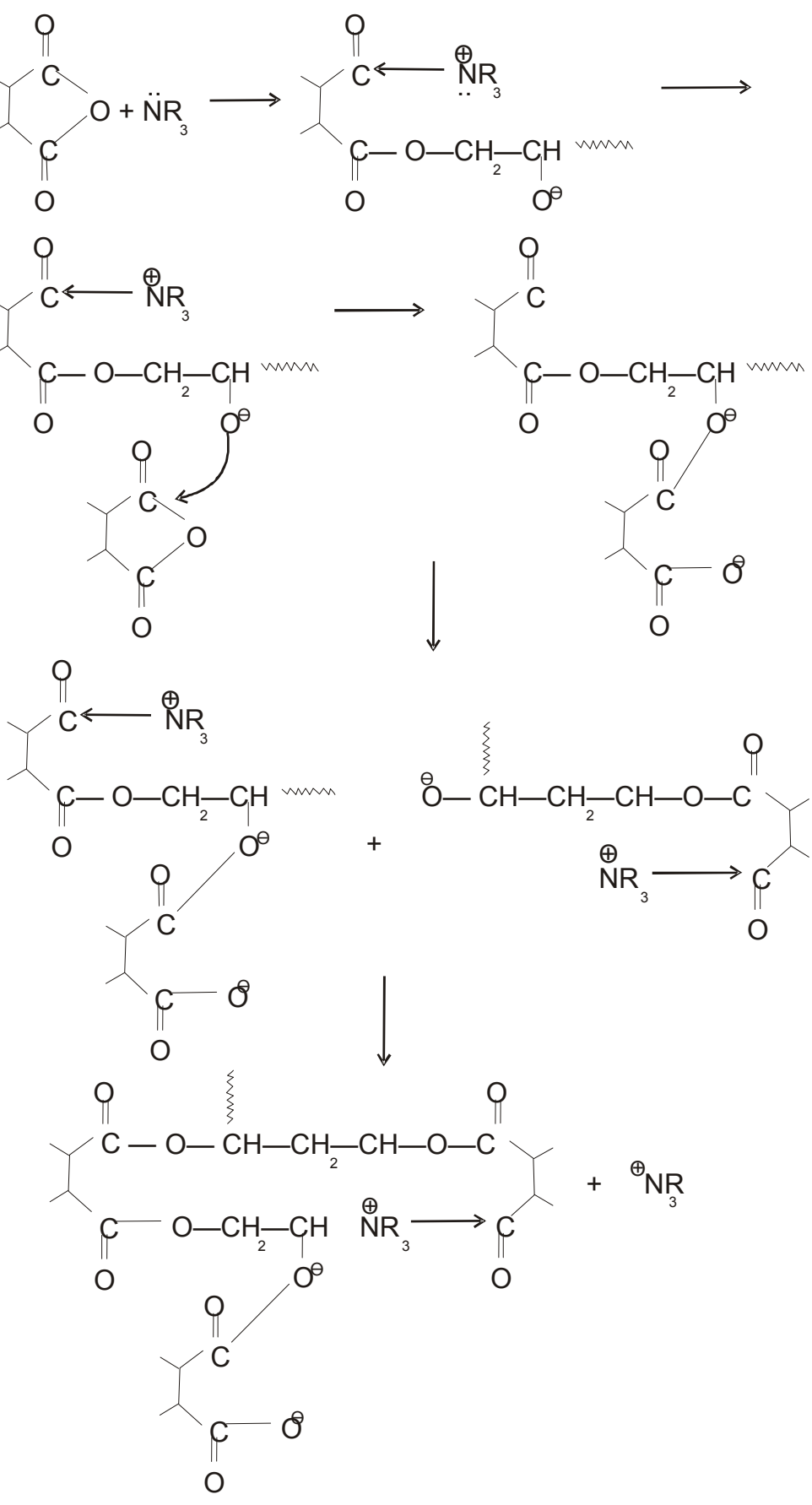

The ring opening mechanism governs the reaction between the epoxy and the anhydride (Unnikrishnan, Thachil, \& Eby Thomas, 2006). The mechanism of anhydride cure is complex and both etherification and esterification can occur. The anhydride must first be converted into its monoacid/monoester for the reaction to occur. Secondary alcohols from the epoxy backbone react with anhydride to give a half ester which in turn reacts with an epoxy group to give the diester. Tertiary amines are used in small amounts to accelerate the curing (Pham \& Marks, 2004). During cure, the lone pair of electrons on the nitrogen atom of amine, help in the ring opening of the anhydride group to form a complex. This in turn reacts with the epoxy group to form an ether linkage.

\subsection{Thermogravimetric Analysis (TGA) of the Oxazolidone Anhydride Blends}

Thermal stability of oxazolidone modified epoxy with stoichiometric amounts of dianhydrides was determined by recording TG/DTG traces in $\mathrm{N}_{2}$ atmosphere at a constant heating rate of $10 \% \mathrm{~min}$. TGA studies were carried out in HIResTGA-2950 Thermogravimetric Analyser and weight loss Vs temperature plots were obtained and are shown in Figure 2-7. 
Table 1, shows the TGA analysis data of anhydride epoxy blends, it is evident that the onset, midpoint and $\mathrm{T}_{\text {end }}$ are of the same order for almost all the blends. It was observed that the char yield progressively increases as the percentage of oxazolidone increased in the blend because of the presence of increased heterocyclic groups in the oxazolidone blends. However, the presence of $50 \%$ oxazolidone in the blend shows a decrease in the char yield, probably because of the splitting of the oxazolidone and anhydride in the blend.

Data obtained during the thermogravimetric studies on various blends was carried out at constant heating rate of $10 \%$ min.

The TGA thermograms show a single sharp degradation for all the oxazolidone-anhydride blends, irrespective of the amount percent of oxazolidone used, indicating compatibility of the system. The above thermograms show a single sharp degradation peak in the region $380-386{ }^{\circ} \mathrm{C}$ which is also indicative of the homogeneity in the networks formed during cure.

\section{Conclusions}

Synthesized linear oxazolidone modified epoxy can be successfully cured using anhydride-BTDA. Anhydride-cured epoxies can be of much use in high temperature resistant polymers and they also exhibit better aqueous acid resistance. Hence, oxazolidone epoxy-anhydride blends can be termed as the polymer of the future in the field of high temperature resistant polymers because in the modern world of plastics, polymers having higher thermal resistance find a very important and significant place.

TGA studies showed that $15 \%$ of the oxazolidone in the blend was sufficient to give maximum increase in thermal stability and that 0.05 mole of catalyst (BDMA) was sufficient.

Thermal studies also prove that thermal stability of the blends containing $15 \%$ of oxazolidone in the blend was better as compared to other ratios and showed minimum rate of degradation in the system. Hence in our study, $15 \%$ of the oxazolidone modified epoxy is optimum for maximum thermal stability of the thermoset.

\section{References}

Callie, D., Pascault, J. P., \& Tighzert. (1990). Reaction of a dispoxide with a diisocyanate in II. Use of an imidazole or a biocked isocyanate catalysts. Polymer Bulletin, 24, 31-38.

Chan, K. S., \& Yi, S. (2001). Synthesis and characterization of an isocyanate-oxazolidone polymer: Effect of stoichiometry. Journal of Applied Polymer Science, 82(4), 879-888. http://dx.doi.org/10.1002/app.1919

Cole, K. C. (1991). A new approach to modeling the cure kinetics of epoxy/amine thermosetting resins. 1. Mathematical development. Macromolecules, 24(11), 3093-3097. http://dx.doi.org/10.1021/ma00011a011

Dušek, K. (1986). Network formation in curing of epoxy resins: Epoxy resins and composites III. Advances in Polymer Science, 78, 1-59.

František, Kolář, \& Jaroslava, Svítilová. (2007). Kinetics and Mechanism of Curing Epoxy/Anhydride Systems, Acta Geodyn. Geomater., 4(3), 85-92.

Frisch, K., Sendijarevic, A., \& Sendijarevic, V. (1987). Studies in the formation of poly(oxazolidones) I. Kinetics and mechanism of the model oxazolidone formation from phenyl isocyanate and phenylglycidyl ether. Selectivity of catalysts. Journal of Polymer Science Part A-Polymer Chemistry, 25, 151-170c. http://dx.doi.org/10.1002/pola.1987.080250113

Ha, Q. Pham, \& Maurice, J. Marks. (2004). Epoxy Resins, Published Online: 15 JUL.

Hong, S. G., \& Wu, C. S. (2000). DSC and FTIR Analysis of The Curing Behavior of Epoxy/dicy/solvent Systems on Hermetic Specimens. Journal of Thermal Analysis and Calorimetry, 59, 711-719. http://dx.doi.org/10.1023/A:1010189301221

Jamshldi, S., \& Talemi, P. H. (2006). Synthesis, characterization and properties of novel thermally stable poly(urethane-oxazolidone) elastomers. European Polymer Journal, 42(8), 1743-1754. http://dx.doi.org/10.1016/j.eurpolymj.2006.02.011

Jan-Eric, E., Nelson, G., Rondan, Lam K., Huynh, Ha Pham, Maurice, Marks, \& Thanh, N. T. (2007). Theoretical Study on Mechanisms of the Epoxy-Amine Curing Reaction. Macromolecules, 40(12), 4370-4377. http://dx.doi.org/10.1021/ma070423m

Javni, I., Guo, A., \& Petrovic, Z. (2003). The study of oxazolidone formation from 9,10-epoxyoctadecane and phenylisocyanate. Journal of the American Oil Chemists Society, 80, 595-600. http://dx.doi.org/10.1007/s11746-003-0744-7 
Merline, J. D., Reghunadhan Nair, C. P., Gouri, C., Sadhana, R., \& Ninan, K. N. (2007). Poly(urethane-oxazolidone): Synthesis, characterisation and shape memory properties. European Polymer Journal, 43(8), 3629-3637. http://dx.doi.org/10.1016/j.eurpolymj.2007.05.032

Min, B. G., Stachurski, Z. H., \& Hodgkin, J. H. (1993). Cure kinetics of elementary reactions of a DGEBA/DDS epoxy resin: 1. Glass transition temperature versus conversion. Original Research Article Polymer, 34(23), 4908-4912.

Min, B. G., Stachurski, Z. H., Hodgkin, J. H., \& Heath, G. R. (1993). Quantitative analysis of the cure reaction of DGEBA/DDS epoxy resins without and with thermoplastic polysulfone modifier using near infra-red spectroscopy. Polymer, 34(17), 3620-3627. http://dx.doi.org/10.1016/0032-3861(93)90046-D

Min, B. G., Stachurski, Z. H., Hodgkin, J. H., \& Heath, G. R. (1993). Quantitative analysis of the cure reaction of DGEBA/DDS epoxy resins without and with thermoplastic polysulfone modifier using near infra-red spectroscopy. Department of Materials Engineering, Monash University, Clayton, Victoria 3168, Australia.

Miren, Blanco, M., Angeles, C., Carmen, C., Riccardi, \& Iñaki, Mondragon. (2005). Mechanistic kinetic model of an epoxy resin cured with a mixture of amines of different functionalities. Polymer, 46(19), 7989-8000. http://dx.doi.org/10.1016/j.polymer.2005.06.117

Petrovic, Z., \& Javni, I. (2002). Process for the synthesis of Epoxidized Natural Oii-Based Isocyanate Prepolymers for Application in Polyurethanes, U.S. Patent 6, 399, 698 B1.

Poisson, N., Lachenal, G., \& Sautereau, H. (1996). Near and mid-infrared spectroscopy studies of an epoxy reactive system Original Research Article. Vibrational Spectroscopy, 12(2), 237-247. http://dx.doi.org/10.1016/0924-2031(96)00027-6

Qipeng, Guo. (1995). Effect of curing agent on the phase behaviour of epoxy resin/phenoxy blends. Polymer, 36(25), 4753-4760. http://dx.doi.org/10.1016/0032-3861(95)99290-B

Santoshi, O., \& Shinichi, Y. (2001). A computational study of base-catalyzed reactions between isocyanates and epoxides affording 2-oxazolidones and isocyanates. Jounral of Computational Chemistry, 22(3), 316-326. http://dx.doi.org/10.1002/1096-987X(200102)22:3\%3C316::AID-JCC1004\%3E3.0.CO;2-5

Steven, S., Guy Van, A., Wendy, Vuchelen, \& Bruno, V. M. (2005). Role of Complex Formation in the Polymerization Kinetics of Modified Epoxy-Amine Systems. Macromolecules, 38(6), 2281-2288. http://dx.doi.org/10.1021/ma047796x

Unnikrishnan, K. P., Thachil, \& Eby, Thomas. (2006). Toughening of epoxy resins. Designed Monomers \& Polymers, 9(2), 129-152 (24).

Wei, Chian, \& Delmar, C. Timm. (2004). Chemical/Mechanical Analyses of Anhydride-Cured Thermosetting Epoxys: DGEBA/NMA/BDMA. $\quad$ Macromolecules, $\quad 37(21), \quad 8098-8109$. http://dx.doi.org/10.1021/ma0492925

Woo, E. M., \& Seferis, J. C. (2003). Cure kinetics of epoxy/anhydride thermosetting matrix systems. Article first published online: 10 MAR.

Younes, M., Wartewig, S., Lellinger, D., Strehmel, B., \& Strehmel, V. (1994). The curing of epoxy resins as studied by various methods. Polymer, 35(24), 5269-5278. http://dx.doi.org/10.1016/0032-3861(94)90479-0

Table 1. TGA analysis of BTDA cured oxazolidone modified resins

\begin{tabular}{|c|c|c|c|c|c|}
\hline Exp. No. & Composition Epoxy/Oxz. & Onset Temp. ${ }^{\circ} \mathrm{C}$ & DTG Maxima & $\mathrm{T}_{\text {end }}{ }^{\circ} \mathrm{C}$ & Char. yield at $600{ }^{\circ} \mathrm{C}$ \\
\hline 1. & Neat Resin & 384.30 & 386.74 & 390.00 & $30 \%$ \\
\hline 2. & $5 \%$ & 379.77 & 383.12 & 396.62 & $32 \%$ \\
\hline 3. & $10 \%$ & 382.69 & 385.49 & 390.00 & $34 \%$ \\
\hline 4. & $15 \%$ & 370.61 & 379.85 & 390.93 & $43.2 \%$ \\
\hline 5. & $25 \%$ & 370.11 & 383.10 & 400.10 & $44.10 \%$ \\
\hline 6. & $50 \%$ & 373.21 & 381.64 & 395.73 & $43.09 \%$ \\
\hline
\end{tabular}




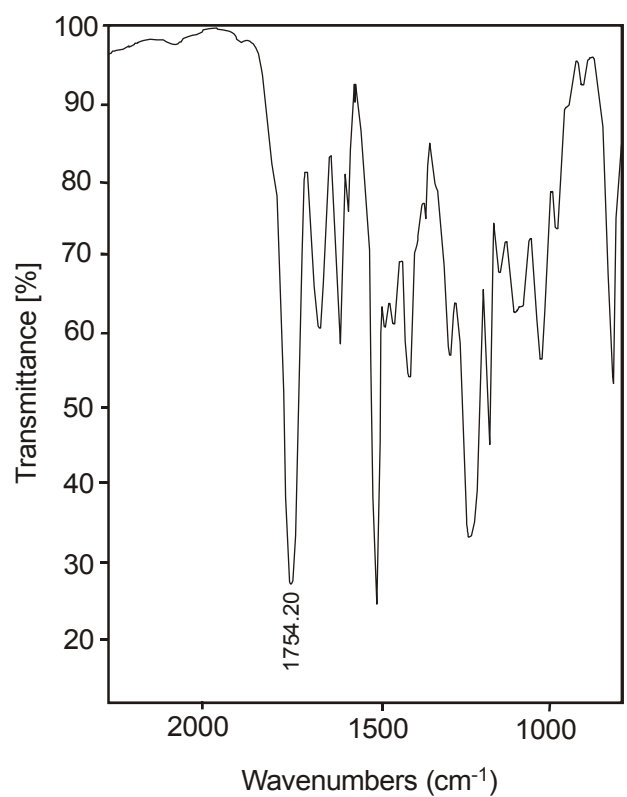

Figure 1. FTIR of the synthesized oxazolidone modified epoxy resin

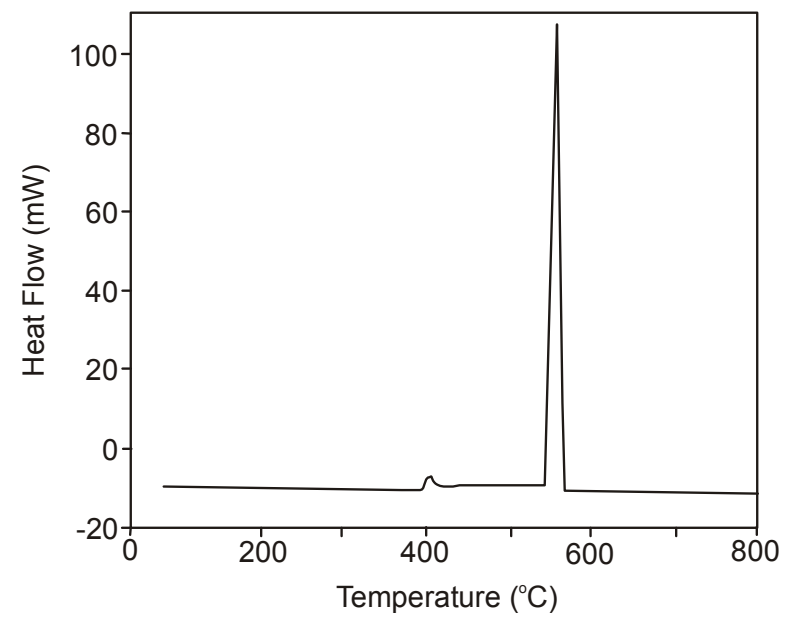

Figure 2. TGA of $1 \%$ oxazolidone in the oxazolidone-anhydride blend

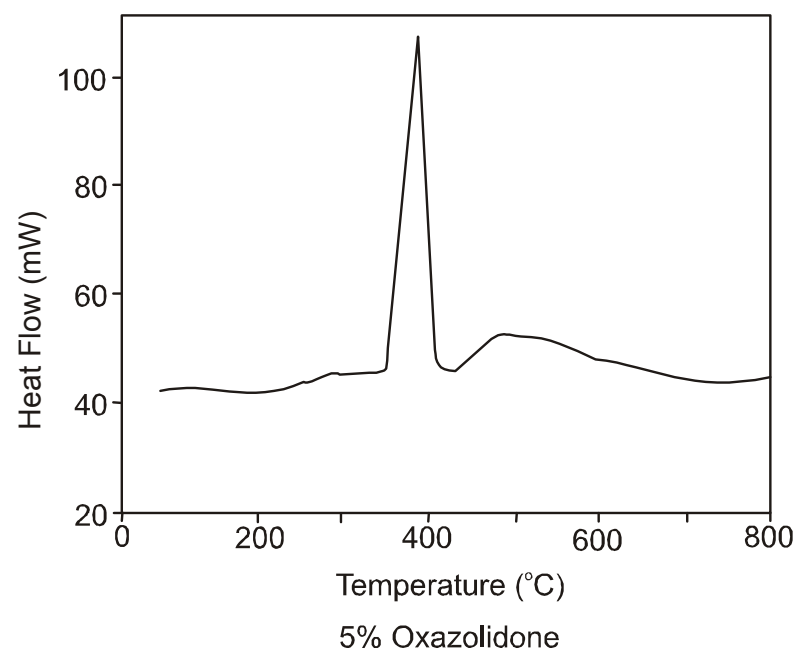

Figure 3. TGA of $5 \%$ oxazolidone in the oxazolidone-anhydride blend 


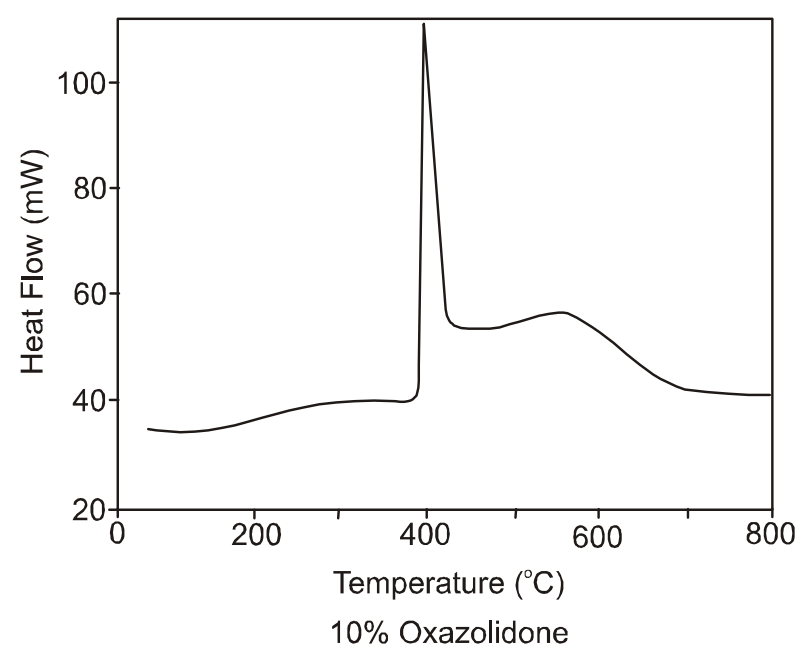

Figure 4 . TGA of $10 \%$ oxazolidone in the oxazolidone-anhydride blend

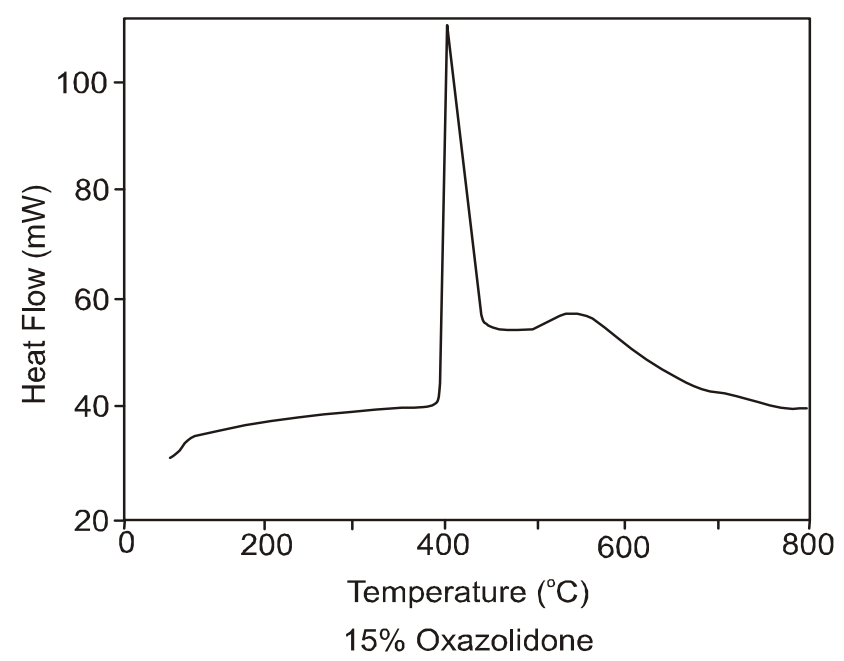

Figure 5. TGA of $15 \%$ oxazolidone in the oxazolidone-anhydride blend

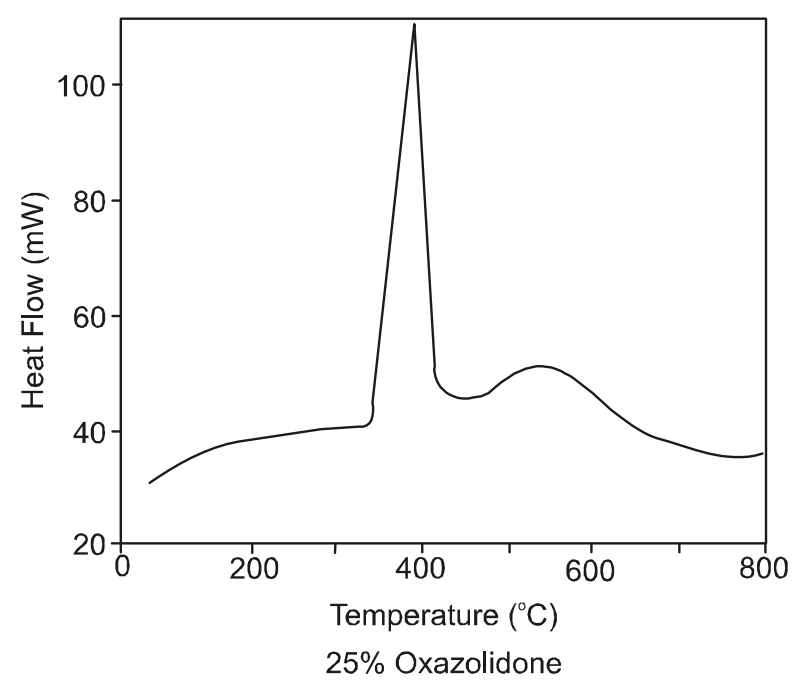

Figure 6. TGA of $25 \%$ oxazolidone in the oxazolidone-anhydride blend 


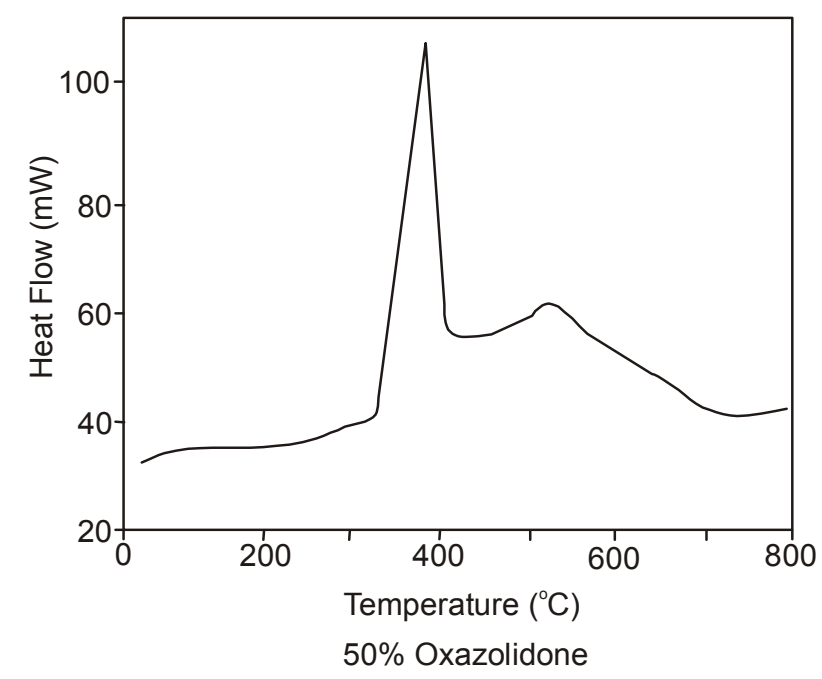

Figure 7. TGA of $50 \%$ oxazolidone in the oxazolidone-anhydride blend 